\title{
GENEALOGIA EPISTÊMICA E NORMAS DE CREDIBILIDADE
}

\author{
EPISTEMIC GENEALOGY AND CREDIBILITY NORMS
}

\author{
BRENO RICARDO GUIMARÃES SANTOS ${ }^{1}$ \\ Universidade Federal de Mato Grosso (UFMT) - Brasil \\ breno.ricardo@gmail.com
}

\begin{abstract}
RESUMO: Neste artigo, eu apresento duas maneiras de conceber uma explicação genealógica do conceito de conhecimento. A primeira delas através da hipótese do estado epistêmico de natureza elaborada por Edward Craig, na qual conhecimento é compreendido como um conceito evoluído a partir do conceito de bom informante. Depois de considerar o projeto de Craig, eu traço um paralelo entre essa abordagem e a explicação valorativa de Miranda Fricker sobre o mesmo conceito. Em seguida, eu apresento e discuto o desenvolvimento social que Fricker oferece à genealogia de Craig, onde ela sugere que as noções de bom informante e de conhecimento são necessariamente dependentes do estabelecimento de uma norma de credibilidade, e que essa norma deve ser vista como inerentemente política. Por fim, defendo uma ilustração a partir do trabalho de Kristie Dotson de como ambas as abordagens genealógicas poderiam explicar e oferecer soluções para falhas dos nossos sistemas epistêmicos.
\end{abstract}

PALAVRAS-CHAVE: Conhecimento. Informação. Resiliência. Normas de credibilidade.

ABSTRACT: In this paper, I present two ways of conceiving a genealogical explanation of the concept of knowledge. The first one is through the epistemic state of nature hypothesis developed by Edward Craig, according to which knowledge is understood as a concept evolved from the concept of a good informant. After considering Craig's project, I draw a parallel between this approach and Miranda Fricker's value-laden account of the same concept. Then, I present and discuss Fricker's social take on Craig's genealogy, in which she suggests that the notions of a good informant and of knowledge are necessarily dependent on the establishment of a credibility norm, and that this norm should be viewed as inherently political. Lastly, I defend an illustration, through Kristie Dotson's work, of how both genealogical approaches could explain and offer solutions to failings in our epistemic systems.

KEYWORDS: Knowledge. Information. Resilience. Credibility norms.

\section{INTRODUÇÃO}

A Epistemologia contemporânea tem sido marcada, em menor ou maior grau, por disputas no campo da análise do conceito de conhecimento. Especialmente no período pós-gettieriano, ${ }^{2}$ a disputa central da Epistemologia tem

$\mathrm{k}^{1}$ Professor adjunto do Departamento de Filosofia da Universidade Federal de Mato Grosso (UFMT).

${ }^{2}$ Em 1963, Edmund Gettier publicou um artigo intitulado "Is justified true belief knowledge?" que virou pedra fundamental da Epistemologia contemporânea. Nele, Gettier lança alguns 
sido em torno da identificação e da correção de seu projeto analítico - da identificação das condições necessárias e suficientes para que algo possa ser classificado como conhecimento. Mais particularmente, qual seria a análise apropriada desse conceito, à medida que o que é apropriado nesse caso é aquilo que descreve mais aproximadamente o nosso uso intuitivo do conceito, as nossas atribuições cotidianas de conhecimento. Em outras palavras, o projeto analítico tradicional poderia ser visto, então, como uma busca de uma intensão que se adeque àquilo que, intuitivamente, tomamos como extensão desse conceito (CRAIG, 1990, p. 1). A disputa sobre a correção de tal projeto é, na maioria dos casos, uma disputa sobre a parte tipicamente epistêmica da análise tradicional do conhecimento. Alguns a chamam de garantia, outros de justificação, outros de conexão causal entre uma crença de que $p$ e o fato de que $p$. E a maneira pela qual essa noção é concebida vai orientar a resposta à pergunta "o que converte crenças verdadeiras em conhecimento?", que é a pergunta central desse projeto analítico, é aquilo que supostamente possibilitará atribuirmos conteúdo ao conceito de conhecimento.

Independentemente de em qual lado da disputa epistemológos e epistemólogas se encontram acerca desse conceito, e da adequação de tal projeto, uma coisa parece clara quando vista de dentro ou de fora: na melhor das hipóteses, não há consenso próximo sobre qual seria a melhor maneira de caracterizar essa noção; na pior das hipóteses, há uma inadequação nessa investigação, que nos leva a cometer uma série de falhas - e que, ainda que ela seja bem sucedida, é extremamente insatisfatória para explicar o conceito de conhecimento de forma completa. Edward Craig é um filósofo reconhecido como estando mais alinhado com essa segunda visão pessimista (CRAIG, 1990, p. 2). Segundo ele, ainda que comecemos nossa investigação sobre as condições de aplicação do conceito de conhecimento comparando tais condições aos casos nos quais intuitivamente dizemos que pessoas conhecem, ainda precisamos preencher uma série de lacunas que parecem não estar devidamente preenchidas nas teorias do conhecimento contemporâneas. Por um lado, por exemplo, como podemos responder aos desafios céticos que parecem nos mostrar que a referência extensional daquilo que intuitivamente tomamos por 'conhecimento' é escassa ou inexistente? Considere, nesse sentido, os desafios céticos lançados tanto a teorias internalistas quanto externalistas sobre a justificação. Em ambos os casos, argumentos céticos parecem mostrar que aquilo que tomamos como o conceito de conhecimento, ainda que possa captar e explicar uma ou outra instância mais sofisticadas de crença verdadeira, falha na tarefa de captar muitos casos cotidianos e ordinários dela. ${ }^{3}$ Esse projeto analítico, da maneira em que está tradicionalmente configurado,

contraexemplos simples ao que ficou conhecido como a definição tripartite de conhecimento, como crença verdadeira justificada. Gettier mostrou que essa definição não era satisfatória, pois ela possuía brechas que permitiam que conhecimento fosse fruto de algum tipo de acidentalidade algo que normalmente consideramos incompatível com o conhecimento. Desde a publicação desse pequeno artigo de apenas 3 páginas, a Epistemologia se viu ocupada da tarefa de tentar fechar esse vão demonstrado por Gettier. O sucesso dessa empreitada é disputável, mas é inegável que ela é significativa para qualquer pessoa que se interesse por questões que envolvem conhecimento e justificação.

${ }^{3}$ Para detalhes e versões dos desafios céticos locais e radicais, ver PRITCHARD, 2005. 
mesmo que esteja de posse de ferramentas conceituais que tentam dirimir ou eliminar os efeitos da dúvida cética nesses casos, tem sido, em grande parte, pouco satisfatório em fazê-lo.

Por outro lado, mesmo quando há um sucesso parcial ou aparentemente total em explicar a falsidade do desafio cético, esse projeto, do ponto de vista de Craig, ainda deixa a desejar em outra frente importante. Por mais firme que o conceito de conhecimento seja, muitas das abordagens definicionais não são capazes de explicar satisfatoriamente por que tal conceito é virtualmente onipresente em todas as comunidades epistêmicas, como ele parece ser (CRAIG, 1990 , p. 2). Em outras palavras, essas abordagens não estariam aptas a explicar satisfatoriamente por que valorizamos esse conceito e o empregamos em contraposição a outros cuja função é captar algo menor ou menos substancial que conhecimento.

Em Knowledge and the state of nature (1990), ${ }^{4}$ Craig propõe uma abordagem crítica à configuração tradicional do projeto analítico. Uma abordagem que não toma como seu objeto central a análise do conceito de conhecimento em termos de uma adequação de uma intensão a uma série de extensões intuitivas. Mas que tenta entender por que usamos esse conceito, qual o seu propósito e seu papel na nossa vida e na nossa economia epistêmica. E, com base nisso, tenta partir para o esforço definicional de identificar a intensão que se adequa a esse propósito, as condições que governam a aplicação do conceito com base no seu uso (CRAIG, 1990, p. 2). Para tanto, Craig tenta estabelecer um cenário genealógico hipotético do desenvolvimento desse conceito, de maneira que tal cenário possa iluminá-lo lançando um holofote sobre seu propósito e sobre seu valor - algo que, segundo ele, o projeto analítico tradicional constantemente falha em fazer.

$\mathrm{Na}$ primeira parte desse artigo eu apresentarei alguns dos pontos mais centrais da proposta genealógica, ou evolutiva, do conceito de conhecimento defendida por Craig. Estabelecendo, em especial, um paralelo entre tal proposta e a explicação valorativa do conhecimento defendida por Miranda Fricker. Meu ponto geral nessa primeira parte será propor um modo de identificarmos no conceito resultante da genealogia de Craig a resiliência epistêmica que Fricker defende ser característica típica do conceito de conhecimento. Na segunda parte do trabalho, discutirei uma abordagem sociopolítica dessa genealogia, também proposta por Fricker, e defenderei que ainda que possamos seguir a autora e identificar limitações da abordagem de Craig para dar conta da normatividade das nossas atividades epistêmicas comunitárias, a proposta dele pode nos servir para compreender um cenário mais amplo de violações dessa normatividade.

Craig começa seu livro nos convidando a explorar não os nossos usos cotidianos do conceito de conhecimento, mas uma situação cotidiana expressa por uma hipótese aparentemente plausível sobre o propósito do conceito, ou pelo

\footnotetext{
${ }^{4}$ Embora algumas ideias iniciais da abordagem de Craig já apareçam em CRAIG, 1986.
} 
menos de um ancestral dele (CRAIG, 1990, p. 2). Sua hipótese central é que o propósito do conceito de conhecimento é identificar bons informantes. Ele nos apresenta um cenário na forma de um estado epistêmico mínimo, que ele chama de estado epistêmico de natureza, ${ }^{5}$ com ancestrais hipotéticos que possuem necessidades cognitivas semelhantes às nossas. Nesse cenário mínimo, esses ancestrais organizados em comunidade precisam formar crenças verdadeiras sobre o seu ambiente, "crenças que podem servir para guiar suas ações a um resultado bem sucedido" (CRAIG, 1990, p. 11). Nesse sentido, nossos ancestrais imaginários não são muito diferentes de nós. Eles compartilham conosco tal necessidade e toda uma gama de disposições intelectuais como fontes de aquisição de muitas dessas crenças. Mas também como nós, esses agentes hipotéticos possuem, por conta de sua vida em comunidade, a possibilidade de se apoiar em outros agentes como fontes de crenças relevantes sobre seu ambiente. Craig supõe que seria vantajoso para esses agentes, para sua sobrevivência nesse estado de natureza (e para a saída dele), que tal possibilidade fosse explorada e que os agentes dessa comunidade agissem como informantes entre si; "o tigre que Fred pode ver e eu não", Craig comenta, "pode estar me caçando e não caçando Fred" (CRAIG, 1990, p. 11). Por isso, em circunstâncias diversas, muitas delas que envolvem a sobrevivência desses agentes, algumas pessoas estarão melhor posicionadas que outras, podendo fornecer informações verdadeiras sobre o mundo, às quais outros agentes não têm acesso a partir de suas próprias disposições intelectuais.

Em um cenário como esse, segundo Craig, é natural supor que a comunidade teria um interesse especial em avaliar essas fontes externas de informação. E junto com esse interesse, essa comunidade desenvolveria conceitos para expressar a qualidade de tais fontes. É nesse contexto que, de acordo com sua proposta, nossos ancestrais hipotéticos introduzem um conceito ancestral de conhecimento. Para Craig, esses agentes precisam de um conceito adequado para avaliar as fontes externas de informação, ou seja, para avaliar a qualidade dos outros agentes de sua comunidade enquanto informantes. A hipótese de Craig, então, é que o conceito de conhecimento evoluiu do conceito ancestral de bom informante. Um conhecedor seria, na aproximação hipotética sugerida, um bom informante.

Mas, se Craig estiver certo, essa explicação captaria apenas a função do conceito, não sua intensão. Ao dizermos que o conceito epistemológico relevante nos é útil na identificação de boas fontes de informação, não dizemos coisa alguma sobre seu conteúdo. Pelo menos à primeira vista. Segundo essa proposta, entretanto, ainda que estejamos falando apenas da função, do propósito de um conceito para os interesses práticos de uma comunidade, é possível iluminarmos o conteúdo desse conceito através da prática de atribuí-lo a pessoas ou a pedaços de informação. Note, entretanto, que isso não é o mesmo que embarcar na mesma

\footnotetext{
5 O uso que Craig faz da noção de "estado de natureza" não deve ser associado, imediatamente, a outros usos correntes, particularmente usos na filosofia política. O propósito de Craig, ao empregar a ideia de um estado epistêmico de natureza é tentar registrar seu exercício hipotético em uma situação anterior ao desenvolvimento de conceitos epistemológicos mais robustos, considerando um cenário no qual pessoas hipotéticas precisariam fazer uso de algumas práticas cooperativas, para se mover de um estado epistêmico simples para um estado epistêmico complexo.
} 
tarefa do um projeto analítico tradicional. O que se busca, nesse caso, não é a delimitação precisa do conteúdo de um conceito para que ele seja confrontado com seu uso no dia a dia. Pelo contrário, o que Craig sugere é a identificação de quais são as propriedades gerais que um agente nesse cenário desejaria que os outros agentes tivessem, para que pudesse se apoiar neles na sua coleta de informações sobre o seu ambiente. E sugere a partir disso, como hipótese, que essas propriedades explicariam a adoção de um conceito particular, nesse caso o conceito de bom informante, iluminando seu conteúdo como consequência. Craig quer investigar por que nossos ancestrais hipotéticos tinham o conceito ancestral de bom informante, qual era a função dele na sua linguagem. Depois de descobrirmos essa função, poderíamos então entender que conteúdo um conceito com tal função teria.

Suponha que eu quero saber se $p$ é o caso. Eu não tenho como saber se $p$ é o caso apenas usando minhas disposições intelectuais, preciso me apoiar nas disposições de outros sujeitos para que eu possa descobrir o valor de verdade de $p$. Que tipo de propriedade eu gostaria que esses outros agentes tivessem para que eu pudesse saber que $p$ ? Bastaria que eles acreditassem verdadeiramente que $p$ e me informassem que $p$ ? Se esse for o caso, como podemos distinguir quando, de fato, esses agentes creem verdadeiramente que $p$ e nos informam que $p$ e quando eles creem falsamente que $p$, mas mesmo assim nos informam que $p$ é o caso? Para Craig, essa distinção é operada justamente pela introdução de um conceito mais complexo, que envolva algo mais do que a mera identificação de agentes que possuem crenças verdadeiras sobre uma questão. Alguém que acredita verdadeiramente em alguma proposição, segundo ele, nos é útil à medida que se destaca na multidão epistêmica, à medida que podemos identificá-lo. E o conceito de bom informante serve justamente para operar essa identificação.

Nesse estado epistêmico inicial, orientado pela prática cooperativa de compartilhamento informações, para ser um bom informante sobre a presença de um tigre, Fred precisa ter uma "propriedade detectável [...] que se correlaciona bem com [ele] estar certo sobre p [a presença do tigre]; uma propriedade, em outras palavras, tal que se o informante a possui, é (pelo menos) bem provável que ele tenha uma crença verdadeira sobre aquela questão" (CRAIG, 1990, p. 18-19). Em linhas gerais, a prática epistêmica cooperativa nesse cenário só será realmente útil para os propósitos práticos desses agentes se ela for discriminativa. Ou seja, é preciso que haja mecanismos públicos que possibilitem fazer a distinção entre bons e maus informantes (FRICKER, 1998, p. 162). Em primeiro lugar, um informante de que $p$ precisa ser competente com relação à verdade de que $p$. Ele precisa acreditar que $p$ quando $p$ é verdadeira e não acreditar que $p$ quando $p$ é falsa, em situações contrafactuais próximas. Mas essa competência, segundo Craig, precisa ser publicamente reconhecida, precisa ser detectável pelos membros da comunidade. Ser um bom informante sobre $p$ nesse empreendimento epistêmico cooperativo envolve, então, as disposições para a verdade por parte de um agente e o reconhecimento de alguma correlação dessas disposições com a verdade de que $p$ por parte de um interlocutor que busca saber sobre a verdade de $p$. E o nosso conceito atual de conhecimento, de acordo com Craig, é uma evolução desse 
conceito ancestral de bom informante. Essa evolução se dá através de um processo que Craig chama de "objetivação" do conceito de conhecimento, onde, a fim de eliminar as subjetividades das avaliações individuais de cada agente na busca por conhecimento, uma comunidade adota uma versão comunitária do que significa ser um bom informante. Ou como Martin Kusch coloca (trocando o conceito de bom informante por "protoconhecedor"),

Craig fala desse desenvolvimento como um processo de "objetivação" do protoconhecimento. [...] Primeiro, o protoconhecimento começa a ser usado para a autoatribuição. Em resposta à questão "quem sabe se p?" membros do grupo começam a investigar suas próprias propriedades indicadoras. Segundo, investigadores começam a recomendar informantes a outros. Isso pode ser feito de uma maneira útil apenas se o caráter indexical ou perspectivo do protoconhecimento é enfraquecido. O informante recomendado deve ser bom aos olhos tanto de quem recomendou quando do recebedor da recomendação. Um movimento adicional nessa dimensão recomendar informantes para ainda mais investigadores torna o protoconhecimento cada vez mais difícil de se conseguir. O ponto final é a ideia de que "alguém é um bom informante sobre $\mathrm{p}$ quaisquer que sejam as circunstâncias particulares do investigador... Isso significa alguém com um alto grau de confiabilidade, alguém que provavelmente estará certo - porque ele deve ser aceitável mesmo para o investigador exigente" (CRAIG, 1990, p. 91). E um investigador muito exigente não aceitará sorte epistêmica ou acidente. Terceiro, investigadores começam a usar "ser recomendado" como uma propriedade indicadora. Esse movimento dilui o requerimento de detectabilidade original. Investigadores começam a chamar alguém de "protoconhecedor" mesmo quando nenhuma das propriedades indicadoras "naturais" originais está à vista. Quarto, no contexto da ação de grupo, investigadores param de se preocupar se a informação necessária é acessível a eles enquanto indivíduos; eles estão satisfeitos se ela é acessível a alguém no grupo. Como resultado eles irão falar de protoconhecimento mesmo fora do contexto do testemunho. O processo de objetivação termina em nosso conceito de conhecimento: "O conceito de conhecer [...] está no fim objetivado do processo; podemos explicar por que há tal fim, e por que ele deve ser visto como importante de se marcar na linguagem" (CRAIG, 1990, p. 90-91) (KUSCH, 2009, p. 66). ${ }^{6}$

Em linhas gerais, segundo essa abordagem, quando identificamos uma pessoa como conhecedora, estamos, em alguma medida identificando essa pessoa como possuidora dessas disposições informativas direcionadas à verdade independentemente de se a identificação é feita no nível individual ou coletivo. ${ }^{7}$

\footnotetext{
6 Tradução nossa - o mesmo se aplica às outras citações que virão ao longo do texto.

7 Craig (1986, p. 215) usa o termo "informante aprovado" para se referir às pessoas reconhecidas com boas informantes. Penso que, na ocasião de uma avaliação mais detalhada da diferença entre informantes identificados no nível individual e informantes que são identificados no nível coletivo,
} 
O que não quer dizer, como Fricker (1998, p. 163-164) menciona, que o conceito de conhecimento deve envolver em sua análise o conceito de bom informante como uma de suas condições necessárias e suficientes. Obviamente que podemos pensar em conhecedores que não são bons informantes, não porque não possuem as disposições informacionais relevantes, mas porque tais disposições não são facilmente detectáveis por uma comunidade. Considere, por exemplo, que Fred está no topo de uma árvore, com visão panorâmica privilegiada do ambiente, e em plenas condições de informar se há um tigre vindo na direção de seu grupo. No entanto, ninguém de sua comunidade sabe onde Fred está. Nesse caso, Fred possui as disposições informativas relevantes direcionadas à verdade, mas sua comunidade não tem acesso a tais disposições. O papel da descrição do bom informante é, na proposta de Craig, o de traçar uma genealogia do conceito de conhecimento, mostrando que sua função é identificar esses bons informantes, e que essa identificação é operada pelo reconhecimento de uma correlação confiável entre as disposições desse agente e a verdade daquilo que se investiga. Se ele estiver certo, não só o conceito de conhecimento pode ser melhor compreendido através da compreensão do seu papel na nossa linguagem, mas também podemos vislumbrar por que ao dizermos que alguém conhece estamos fazendo um juízo de valor que aparentemente não fazemos quando dizemos que alguém meramente crê em uma proposição.

Em 'Knowledge and the test of time' (2009), Fricker desenvolveu uma maneira de explicar a questão do valor do conhecimento que se aproxima bastante da proposta genealógica de Craig e que aponta para a realização dessas tarefas de investigação acima: a tarefa de iluminar o conceito de conhecimento através de seu propósito e a tarefa de entender por que conhecimento é mais valioso que mera crença verdadeira. Vejamos como isso se dá.

\section{II}

Primeiro, considere o seguinte exemplo apresentado e discutido por Fricker (e levemente modificado aqui): você acorda à noite ouvindo o barulho do alarme de incêndio do prédio. Você forma a crença de que há um incêndio; você então ajuda a colocar todo mundo em segurança e liga para os bombeiros. Sua crença é verdadeira, porque há de fato um incêndio no porão; mas o alarme de incêndio está com problema e disparou aleatoriamente, sem ser ativado pela fumaça desse incêndio. Você tem uma crença verdadeira, mas não tem conhecimento. Mas e daí? Por que o estado de conhecimento nesse caso seria mais valioso? Você conseguiu salvar todo mundo e ligar para os bombeiros. O valor dado a mera crença verdadeira pelo fato de que ela é verdadeira parece exaurir, nesse caso, o valor da contraparte, o valor do conhecimento (FRICKER, 2009, p. 121).

O ponto de Fricker é o seguinte: ainda que concebamos que há um valor diferenciado na posse de conhecimento que não existe na posse de mera crença verdadeira - e parece haver uma intuição pré-teórica nesse sentido, dado que

poderíamos fazer a distinção entre bons informantes (para mim) e informantes aprovados (por minha comunidade). Não me deterei nesse ponto aqui. 
usamos termos diferentes para tratar dos dois estados e dado que nossa linguagem denuncia uma certa preferência pela posse de conhecimento ${ }^{8}$ - ainda carecemos de uma explicação satisfatória sobre a natureza desse valor diferenciado. O que há no conhecimento, que não é apenas a própria presença da crença verdadeira, que faz com que ele seja um estado epistêmico mais valioso?

Fricker vai buscar inspiração em um lugar familiar na discussão sobre justificação epistêmica e sobre o valor do conhecimento para poder lidar com essa questão, e oferece aquele que ela pensa ser o tratamento adequado para o problema do valor. Esse lugar familiar é o diálogo entre Sócrates e Mênon (PLATO, 2005) sobre a diferença entre conhecimento e mera opinião correta, que é, com frequência, identificado como um dos berços do debate epistemológico contemporâneo. Não reproduzirei o diálogo por completo aqui, mas quero apresentar pelo menos as ideias gerais contidas na passagem.

Em linhas gerais, a pergunta central do diálogo se alinha com o exemplo do incêndio apresentado acima, e é a seguinte: dado que pessoas que sabem o caminho correto para Larissa, a cidade grega, e as pessoas que apenas acreditam verdadeiramente que tal caminho é o caminho para Larissa podem apontar corretamente esse caminho, parece plausível pensar que as indicações de ambas as pessoas, a indicação correta do caminho, são igualmente boas em cumprir tal função. Se as duas são certeiras em sua função, elas fornecem o mesmo bem para a pessoa que precisa chegar a Larissa. Comparando com o caso do incêndio, uma pessoa que acredita verdadeiramente que há um incêndio porque ela sentiu a fumaça e viu o fogo e uma pessoa que acredita verdadeiramente que há um incêndio por causa do alarme desregulado chegam à mesma conclusão, tomam o mesmo curso de ação e salvam a mesma quantidade de vidas. Então qual a importância se sabemos ou não o caminho pra Larissa, ou se sabíamos ou não que havia de fato um incêndio no prédio? Mera crença verdadeira, mera opinião correta, parece fazer todo o trabalho necessário em ambos os casos.

Podemos pensar ainda, como o faz Sócrates (PLATO, 2005, p. 129), em alguém que sempre tem uma opinião correta sobre o caminho para Larissa, mesmo sem nunca ter ido à cidade. Nesse caso, sempre que essa pessoa informar sobre o caminho para Larissa, mantendo-se tudo igual, esta será uma informação correta. Assim, chegamos então à pergunta de Mênon, que é considerada como uma das origens dessa nossa discussão: se esse é o caso, por que então crença e conhecimento são tratados como duas coisas diferentes, sendo uma considerada muito mais valiosa do que a outra?

Segundo Fricker, para responder a essa questão, à questão do valor do conhecimento, precisamos abordá-la tendo como ponto de partida a avaliação das maneiras pelas quais conhecer nos é útil na nossa prática de aquisição de verdades, como um todo (FRICKER, 2009, p. 128). E essa avaliação, ela afirma, já estava

\footnotetext{
${ }^{8}$ Quando dizemos, por exemplo, "eu sabia que a janela do quarto estava aberta!" como uma maneira de dizer que falávamos de uma posição de segurança quanto ao fato da janela estar fechada ou não; ou ainda quando asserimos algo sem modular essa asserção com "creio que", "acho que", "talvez seja o caso que", etc., nos colocando como conhecedores, em uma posição epistemicamente mais forte (pelo menos do nosso próprio ponto de vista) sobre aquele assunto.
} 
presente no próprio diálogo entre Sócrates e Mênon. Ao responder a Mênon, Sócrates afirma que estados de conhecimento são mais valiosos que meros estados de opinião correta porque estados de conhecimento não estão apenas fixados, mas essa fixação é também em grande medida estável. Para Sócrates, ainda que opiniões corretas possam estar fixadas e ser capazes de nos apontar para a verdade, opiniões corretas não são necessariamente estáveis. Seu estado de fixação é efêmero e tais opiniões estão sempre "fugindo da alma de uma pessoa" (PLATO, 2005, p. 130). A diferença central de mera opinião correta para conhecimento, segundo Sócrates, seria então o fato de que conhecimento é um estado de opinião correta cuja razão da correção foi descoberta, fazendo com que esse estado não só esteja fixado "na alma" de determinada pessoa, mas que cuja fixação seja estável nessa "alma". O sentido de conferir estabilidade para a fixação é, segundo Fricker, o de estar ciente das razões ou das evidências que fazem com que determinada crença, ou opinião, seja verdadeira. O conhecimento é mais valioso que mera crença verdadeira, então, segundo essa leitura, porque conhecimento é um estado de estabilidade do sucesso em atingir a verdade de determinada proposição.

Quem tem familiaridade com as passagens sobre o conhecimento nesses diálogos platônicos provavelmente lembra da metáfora central de Sócrates ao explicar a fixação e a estabilidade do conhecimento. Sócrates fala que conhecimento é mais valioso que mera opinião correta porque o conhecimento está "acorrentado", tal qual a estátua de Dédalo. Diz a lenda que a estátua de Dédalo era tão bem feita, tão próxima de um figura viva real, que as pessoas precisariam acorrentá-la para que ela não fugisse. Segundo Sócrates, uma estátua de Dédalo solta não teria qualquer valor substantivo, dado que ela poderia fugir a qualquer momento, mesmo estando fixada ao chão. Uma mera opinião correta, segundo ele, seria do mesmo jeito. A possibilidade de esta opinião correta "fugir" faz com que seu valor não seja muito alto. Ela teria valor se, além de estar fixada, também fosse estável, fosse "acorrentada" de modo que sua fuga fosse dificultada. Conhecimento é, nesse sentido, crença verdadeira "acorrentada" - crença verdadeira que não se pode facilmente perder.

Na visão de Fricker, a resposta de Sócrates, e a metáfora nela incluída, aponta para uma ideia de que o valor do conhecimento está na tendência em "sobreviver ao teste do tempo" graças a algum tipo de vantagem racional. E foi esse tipo de leitura que, de acordo com ela, foi negligenciado pelas teorias epistemológicas contemporâneas que buscaram oferecer uma resposta à questão do valor. Para ela, por serem teoricamente partidárias, no sentido de que estão intimamente alinhadas a uma agenda teórica específica, muitas das abordagens epistemológicas que tentaram lidar com essa questão a trataram como uma tarefa associada à tarefa de definir em seu favor outras disputas epistemológicas, como a disputa sobre qual a maneira correta de caracterizar o elemento justificacional da definição tradicional de conhecimento. Fricker argumenta que misturar essas duas questões ajuda a distorcer o debate e esconder um dos aspectos principais do conhecimento como algo valioso.

Desse ponto de vista, teorias epistemológicas que parecem se destacar dentre as inúmeras respostas à questão do valor só estariam de fato se destacando 
porque partem do pressuposto de que aquilo que torna o conhecimento algo mais valioso que mera crença verdadeira não seria nada mais do que o próprio elemento que diferencia essas noções. E como esse elemento, em primeiro lugar, é visto como o elemento justificacional e, em segundo lugar, parece estar sendo validado pela ideia platônica de que conhecimento tem como peculiar um aspecto racional, esse acabou sendo o foco dessas teorias - e a qualidade desse elemento justificacional passou a ser a medida do seu sucesso em responder à questão do valor.

Teorias do crédito, ${ }^{9}$ por exemplo, tendem a defender que o que confere um valor especial ao conhecimento é o crédito atribuído ao agente que crê verdadeiramente, e de maneira adequada, em uma proposição. Conhecimento, sob essa perspectiva, é crença verdadeira creditável ao agente. Esse crédito então é transferido para o estado de conhecimento, e é isso que faz com que esse estado seja mais valioso que mera crença verdadeira, mera crença formada sem o intermédio de um trabalho epistêmico adequado por parte do agente independentemente de como a adequação desse trabalho seja definida. Já uma teoria das virtudes como a de Linda Zagzebski, ${ }^{10}$ segundo a qual, em linhas gerais, conhecimento é crença verdadeira que contém um componente motivacional virtuoso por parte do agente, o valor especial do conhecimento seria o valor desse componente motivacional. De acordo com uma posição como essa, crenças verdadeiras formadas a partir de um componente motivacional bom, seriam crenças admiráveis, mesmo se essas crenças fossem fúteis, triviais, moralmente repreensíveis. A admirabilidade delas é o valor adicional, o valor especial do qual falamos (FRICKER, 2009, p. 125).

Fricker pensa que há um problema genérico na maneira pela qual a questão do valor foi tratada, que é comum tanto a essas duas abordagens acima quanto à grande maioria das tentativas de responde-la. Pensar, por exemplo, que damos valor ao conhecimento porque damos valor a esses elementos justificacionais é, segundo ela, "colocar o carro na frente dos bois" (FRICKER, 2009, p. 125). Para ela, nós damos valor a esses elementos justificacionais porque nós damos valor ao conhecimento que normalmente eles nos conferem. E não o contrário. Uma maneira de expressar essa ideia de modo mais direto seria nos perguntarmos "por que é mais valioso possuir verdades em forma de conhecimento?" (FRICKER, 2009, p. 126). Essa pergunta inverte a direção da análise e obscurece os tratamentos tradicionais que foram oferecidos à questão do valor. Precisamos de muitas crenças verdadeiras, mas por que as precisamos em uma forma específica, na forma de conhecimento? Desse ponto de vista, parece estranho alegar que precisamos das crenças nessas formas porque assim elas nos concedem crédito, ou porque elas nos concedem motivações virtuosas. Isso é simplesmente estranho. As crenças verdadeiras não parecem nos conceder isso. Na melhor das hipóteses, se essas teorias estiverem corretas, somos nós que nos relacionamos com as crenças verdadeiras através desses atributos, e não os atributos que saltam das crenças e

\footnotetext{
9 Ver, por exemplo, GRECO, 2003.

${ }^{10}$ Ver, por exemplo, ZAGZEBSKI, 1996.
} 
se prendem em nós. Sob essa perspectiva, o valor da verdade ${ }^{11}$ em suas diferentes aparições, não deve ser confundido com o valor do elemento justificacional que se conecta cognitivamente com a verdade.

Essa confusão, segundo Fricker é fruto daquilo que ela chama de uma "presunção sincrônica não-autorizada", uma visão acerca do valor do conhecimento que trata a questão como se fosse algo a ser decidido através da comparação entre meras crenças verdadeiras e casos de conhecimento em um instante específico do tempo (FRICKER, 2009, p. 127). Presunções sincrônicas, eu diria, não são algo incomum na Epistemologia individualista tradicional. Afinal, grande parte das questões sobre a natureza do conhecimento e da justificação toma como objeto de análise casos de crenças verdadeiras em um tempo $t$, com base em evidências possuídas naquele tempo $t$. Um dos trunfos de abordagens sociais de epistemologia, das quais Fricker é uma das representantes de maior destaque, foi justamente romper com essa visão sincrônica das práticas de conhecimento. Voltarei a esse ponto mais à frente.

Essa presunção ocultaria a possibilidade de concebermos o valor do conhecimento como algo mais do que a simples apreensão cognitiva localizada acerca de uma proposição particular. Dificultaria a possibilidade de identificarmos o valor do conhecimento em algo que nos ajudaria a reter nossas crenças verdadeiras ao longo do tempo, uma visão que Fricker chama de "diacrônica" acerca da nossa prática epistêmica. Algo que estaria sugerido já na resposta que Sócrates dá a Mênon, quando ele fala da estabilidade do conhecimento (FRICKER, 2009, p. 128). A essa estabilidade, a esse valor especial do conhecimento, Fricker dá o nome de resiliência. Segundo sua posição, precisamos abandonar uma concepção sincrônica da nossa prática epistêmica e adotar uma concepção diacrônica dela,

[Concebendo] os sujeitos epistêmicos como posicionados no tempo para que possamos revelar a diferença crucial: meras crenças verdadeiras estão tipicamente mais vulneráveis a serem perdidas frente a contraevidência enganadora. Reconsidere a estrada para Larissa - e eu devo tentar ser mais epistemologicamente não-partidária o possível - supondo apenas que Sócrates assume corretamente [...] que conhecimento tipicamente envolve chegar à crença verdadeira com base em alguma evidência ou raciocínio adequados. O valor extra de conhecer a rota em oposição a meramente ter uma opinião verdadeira é que, ao longo do tempo, é provável que você encontre contraevidências (você conversa com um passante que diz que é para o outro lado, você vê um poste virado como pegadinha, apontando para o caminho errado) e se você tem alguma apreensão da evidência para sua crença, como você tipicamente terá se você tiver conhecimento, então você está em uma posição melhor para pesar a nova evidência. Você fica então menos suscetível a abandonar sua crença verdadeira por uma falsa frente à evidência enganadora. O ponto é que possuir uma crença verdadeira

11 Não confundir com o valor de verdade, um atributo de proposições, as quais podem ser verdadeiras ou falsas. 
na maneira típica do conhecimento reduz a classe de contraevidências que irão te enganar (FRICKER, 2009, p. 129).

O ponto geral de Fricker é que o valor do conhecimento não está em um elemento justificacional particular atrelado às nossas crenças verdadeiras. Mesmo que exista uma tendência, por parte da epistemologia contemporânea, em interpretar os comentários de Sócrates apenas como uma defesa explícita de uma análise do conhecimento como crença verdadeira justificada. Esse valor está na tendência que essas crenças têm de "sobreviver ao teste do tempo", da sua resiliência derivada de alguma vantagem racional, seja esta qual for. Para ela, nós valorizamos o conhecimento porque valorizamos a função da posse de verdades ao longo do tempo, diacronicamente. Ou seja, nós valorizamos o conhecimento porque sua resiliência frente ao teste do tempo é conducente à nossa retenção dessas verdades quando confrontados com contraevidências enganadoras. Assim, o valor do conhecimento reside nessa tendência a sobreviver a desafios contraevidenciais enganosos, tendência esta que está associada a uma posição na qual o agente está, que possibilita que ele pese contraevidências enganadoras contra as evidências que ele possui para sua crença verdadeira com status de conhecimento.

É importante notar, entretanto, que o trabalho de Fricker aqui não é o de oferecer uma definição de conhecimento em termos de crença verdadeira resiliente. A posição dela é que a resiliência é um atributo típico do conhecimento, mas não necessário. É uma generalização que permite que haja casos em que o conhecimento não possua resiliência, não possua essa tendência de explorar uma posição racional vantajosa para se contrapor a contraevidências enganadoras. Ou permite que tal resiliência, ainda que presente, não possua seu valor normal. Isso porque podemos pensar em casos de conhecimento que são diacronicamente insipientes, que por sua própria natureza não possuem função além de um momento particular no tempo. Nesses casos, Fricker admite, conhecimento não possui o valor que ele tipicamente possui. (FRICKER, 2009, p. 132).

Com esse ponto, ela sugere que rejeitemos outra suposta presunção do tratamento tradicional do problema do valor, que ela chamou de "presunção analítica", a ideia segundo a qual o valor distintivo do conhecimento deve estar contido em qualquer elemento que dizemos converter mera crença verdadeira em conhecimento (FRICKER, 2009, p. 133). Uma vez que aceitamos que o conhecimento tem como valor básico sua resiliência, podemos entender que o valor do conhecimento não tem sua explicação atrelada a uma condição garantidora necessária, mas sim a uma generalização sobre como a posse estável de crenças verdadeiras nos ajuda, a longo prazo, a continuar fixando e estabilizando crenças verdadeiras dentro do nossa estrutura doxástica.

Se Fricker estiver certa, essa posição representa uma separação considerável da maneira que a questão do valor tem sido tratada na epistemologia recente. Em particular, irei sugerir na segunda parte desse trabalho, ela se afasta tanto do tratamento dispensado pela epistemologia tradicional a essa questão que parece 
natural ver sua proposta aportando e encontrando seu espaço na epistemologia social, onde tal explicação do valor do conhecimento pode oferecer insights sobre alguns problemas identificados nas nossas práticas de conhecimento em comunidade.

É esse afastamento do projeto epistemológico tradicional que aproxima as posições de Craig e Fricker - e a própria Fricker reconhece essa aproximação (FRICKER, 2009, p. 137). Ambos rejeitam a centralidade da análise tradicional do conhecimento endossada pela epistemologia contemporânea, e fazem um apelo a uma investigação sobre a função do conhecimento (e suas consequências epistêmicas) na nossa vida prática. De um lado, como vimos, Craig defende que o conceito de conhecimento é valioso ${ }^{12}$ para nós à medida que nos ajuda a identificar bons informantes na nossa comunidade. Onde bons informantes são aqueles agentes epistêmicos que não só são competentes em atingir a verdade sobre determinadas proposições, mas são reconhecidos publicamente como sendo, possibilitando sua identificação como fontes confiáveis de compartilhamento de informações naquela comunidade. Do outro lado, Fricker defende que o conceito de conhecimento é valioso à medida que ele explicita a estabilidade de crenças verdadeiras e, por consequência, das disposições dos agentes possuidores dessas crenças.

Craig não está explicitamente preocupado em oferecer uma discussão do conceito de conhecimento em termos de estabilidade e resiliência ao longo do tempo, como é o caso de Fricker. Ele está mais preocupado em entender o conceito em termos da identificação do potencial compartilhador de cada agente epistêmico em uma comunidade. Aquele agente identificado como bom informante no estado de natureza é um agente identificado como compartilhador confiável de informações. Aquilo que esperamos de conhecedores, segundo Craig, é o que nossos ancestrais hipotéticos esperavam de bons informantes - esperamos que não só essas pessoas creiam verdadeiramente em uma proposição, mas que o façam de modo competente, de modo confiável.

Eu arriscaria acrescentar: de modo estável. Me parece que o apelo ao potencial compartilhador presente no cenário hipotético de Craig nada mais é do que o apelo a uma certa estabilidade na formação e transmissão de crenças verdadeiras. Quando ele exige que um agente seja competente e que sua competência seja reconhecida, ele estaria exigindo que esse agente seja visto como um compartilhador estável de verdades. Ser um bom informante é ser um compartilhador estável e ser reconhecido como tal. Se para Fricker, o valor do conhecimento reside em grande medida na resiliência das crenças em questão frente a contraevidências enganadoras, o valor do conhecimento para Craig residiria na resiliência das crenças compartilhadas frente a contraevidências enganadoras, o que possibilita um sucesso razoável no trabalho cooperativo que é o compartilhamento de informações no cenário epistêmico mínimo. O propósito

\footnotetext{
${ }^{12} \mathrm{O}$ trabalho de Craig não está preocupado necessariamente com a questão acerca do valor do conhecimento. Mas concordo com Fricker (2009, p. 137) quando ela defende que ele pode ser lido como uma extensão dessa discussão. Afinal, não é difícil enxergar o valor do conhecimento uma vez que entendemos os benefícios que a posse desse conceito nos proporciona.
} 
do conceito de conhecimento, nas duas abordagens é sinalizar, por um lado, informações estáveis e, por outro, informantes estáveis.

A abordagem genealógica de Craig, assim, parece encontrar um certo tipo de complementariedade na posição valorativa de Fricker. No que segue, apresentarei uma maneira pela qual as duas posições se distanciam. Em particular, apresentarei uma reformulação social da genealogia de Craig feita por Fricker e irei apontar que, quando lançada à prática epistêmica efetiva no mundo atual, a abordagem de Craig perde força.

\section{III}

Na primeira parte do trabalho, vimos como Craig apresenta sua explicação genealógica do conceito de conhecimento, discutindo em que sentido podemos encarar esse conceito a partir de um entendimento da sua função na nossa linguagem. Na presente seção, quero apresentar de que maneira esse tipo de explicação é adotado por Fricker, como uma forma de explorar a figura do conhecedor como constituído socialmente e como alguém afetado pelas relações de poder social em sua comunidade.

Em 'Rational authority and social power' (1998), Fricker se propõe a explorar a genealogia de Craig para explicar, em linhas gerais, a relação entre autoridade racional e poder social. Nesse trabalho ela está preocupada em desfazer pelo menos dois mitos sobre o tratamento do sujeito conhecedor. Em primeiro lugar, ela quer rejeitar a ideia, presente na tradição, de que este sujeito é o resultado apenas de considerações puramente epistemológicas, sem qualquer influência de aspectos sócio-políticos da prática epistêmica. Em segundo lugar, ela pretender rejeitar a ideia de teóricos associados àquilo que ela chamada de uma concepção pós-moderna da razão e da verdade, que defendem que não há nada de realmente epistêmico nessas noções, pois elas seriam apenas expressões de poder social e nada mais (FRICKER, 1998, p. 160).

O ponto geral de Fricker é intermediário. Ela defende que a normatividade das nossas práticas pode até ter origem em preocupações genuinamente epistemológicas e racionais - como é o caso da normatividade mínima presente no tratamento genealógico de Craig. Mas quando lançadas à prática efetiva socialmente localizada, elas podem, com frequência, estar orientadas por estruturas de poder social. E é dentro do próprio tratamento de Craig, de seu cenário minimamente social, que Fricker quer investigar essa orientação.

Lembremos que o trabalho de Craig consiste em explorar de que maneira, da perspectiva de um agente ancestral no estado epistêmico de natureza, o conceito de conhecimento - um ancestral dele, pelo menos - pode ser distinguido do conceito de crença verdadeira. Lá, a maneira de conduzir essa exploração se deu através da hipótese de que as condições de aplicação do conceito relevante poderiam ser explicadas através do reconhecimento do papel que esse conceito teria para tal agente. Dada a necessidade da eficácia de uma prática informativa cooperativa nesse cenário original, Craig supõe que esses sujeitos encontraram a 
necessidade de criar mecanismos de identificação pública das propriedades típicas que outros sujeitos possuem, e que apontam para essa eficácia. Daí surge o conceito de bom informante, o antepassado linguístico do conhecedor. O bom informante, como vimos, é alguém que é contrafactualmente competente em formar crenças sobre o mundo e cuja competência é reconhecida por seus pares. Aquilo que indica a competência desse sujeito com relação a uma proposição $p$, então, indica também que esse informante provavelmente está certo com relação a $p$.

Fricker pensa que há uma limitação central nessa descrição. Para ela, o trabalho especulativo de Craig é importante no sentido em que ele estabelece uma forte relação entre uma hipótese plausível e a atualidade do uso do conceito de conhecimento, entre a genealogia e a história (FRICKER, 1998, p. 165). Sua explicação é útil porque nos ajuda a entender de que modo as diversas comunidades humanas que possuem alguma versão do conceito de conhecimento o possuem justamente por uma necessidade de estabelecer estratégias coletivas para a busca da verdade. No entanto, ele deixa de fora - por contingências metodológicas - os aspectos distintivamente políticos dessa prática. Para Fricker, a genealogia do conhecimento de Craig deveria se tornar distintivamente política quando nos afastamos paulatinamente do estado de natureza minimamente social e adentramos cenários socialmente complexos nos quais nossas práticas epistêmicas estão inseridas (FRICKER, 1998, p. 166).

Tome, por exemplo, as propriedades centrais do bom informante de Craig e o exemplo seguinte. Um sujeito no estado de natureza quer descobrir se determinada amora é um tipo de amora venenosa ou um tipo de amora nãovenenosa. Esse sujeito não tem como descobrir a verdade sobre essa questão a partir de seus atributos intelectuais, apenas. Ele então aborda uma outra pessoa de sua comunidade para consultar sobre a questão. Segundo Craig, um bom informante sobre o potencial fatal da amora deve, pelo menos, ser competente sobre a questão e reconhecido como tal - individual ou coletivamente. Mas o que acontece quando alguém de fato é competente sobre uma questão como essa, possui propriedades indicadoras a esse respeito, mas não tem suas propriedades reconhecidas em sua comunidade?

Fricker distingue entre autoridade racional e credibilidade de um sujeito em uma prática epistêmica cooperativa. Um sujeito possui autoridade racional, segundo ela, se ele é competente sobre uma determinada questão (ou sobre um conjunto de questões) e se ele é digno de confiança no que tange ao compartilhamento de informações sobre a questão (ou sobre um conjunto de questões). Ser digno de confiança, para ela, é ser confiável em seu papel de informante sobre a questão. Podemos pensar, por exemplo, que alguém é competente sobre a verdade de $p$, mas sempre mente quando perguntado sobre p. Nesse caso, essa pessoa é competente, mas não digna de confiança quando o assunto é $p$. Um sujeito tem credibilidade, por outro lado, se ele é reconhecido como tendo as propriedades indicadoras de competência e confiança sobre uma questão (ou um conjunto de questões). Para Fricker, quando uma pessoa tem 
autoridade racional e tem credibilidade, ela é uma boa informante (FRICKER, 1998, p. 167).

O problema que se coloca é o seguinte. É possível que uma pessoa tenha autoridade racional sobre uma questão, mas nunca ser reconhecida como tal. Considere, por exemplo, o caso do desconhecimento sobre o paradeiro de Fred que eu mencionei acima; ou ainda o caso de alguém que tem um histórico de erros quando perguntado sobre a diferença entre amoras venenosas e nãovenenosas, mas que recentemente aprendeu a fazer a distinção e não erraria se perguntado sobre, tampouco mentiria sobre a questão. Essa pessoa não ganha credibilidade porque ainda não tem um registro de acertos a este respeito. Mas ela definitivamente possui autoridade racional no sentido defendido por Fricker. É possível também que alguém tenha credibilidade, mas não possua autoridade racional sobre a questão. Alguém, por exemplo, que chutou acertadamente a maioria das suas respostas sobre o veneno das amoras e por isso é tomado pela comunidade como uma fonte confiável de informações sobre o assunto. Nesse caso, Fricker defende que essa pessoa tem mera credibilidade e não credibilidade causada por suas disposições internas relevantes (FRICKER, 1998, p. 167).

No entanto, não são só casos de acidentalidade e falta de registro positivo que fazem com que esses desencontros entre autoridade racional e credibilidade aconteçam. Fricker está preocupada com uma tendência à corrupção das práticas de informação, quando elas estão inseridas em cenários sociais complexos. Corrupções que podem tanto ser individualmente deliberadamente causadas ou estarem arraigadas às estruturas políticas e sociais que governam a prática epistêmica.

Para ela, há na relação entre a posse de autoridade racional e a atribuição de propriedade indicadora uma regulação por uma norma de credibilidade, que identifica como bons informantes aqueles que apresentam as propriedades indicadoras relevantes. No cenário epistêmico de Craig, haveria uma ética cooperativa segundo a qual ao reconhecer uns aos outros como fins em si mesmos e como interessados nos mesmos fins epistêmicos, os investigadores atribuem credibilidade toda vez que percebem as propriedades indicadoras de fato. $\mathrm{O}$ problema é que, quando socialmente manifestada em um contexto social mais complexo, essa ética cooperativa poderá ser comprometida por práticas de desinformação e por falhas epistêmicas politicamente motivadas - e, com ela, a norma de credibilidade também estaria comprometida (FRICKER, 1998, p. 168).

Fora do estado de natureza, o poder social seria uma maneira comum de distorcer essa ética cooperativa e sua norma de credibilidade. Para Fricker, nesses cenários, as avaliações normativas não mais são feitas tendo como objeto as propriedades indicadoras de fato, mas sim as propriedades indicadoras funcionais, que podem ou não ser confiáveis em apontar para bons informantes. A posse dessas propriedades, em muitos contextos, seria consequência da posse ou da ausência de um posicionamento social e político vantajoso. Segundo Fricker,

É possível que haja (pelo menos em sociedades reconhecidamente como a nossa) alguma pressão social sobre a norma de credibilidade para imitar estruturas de 
poder social. Onde essa imitação gera um descompasso entre a autoridade racional e a credibilidade - de modo que aos poderosos tende a ser dada mera credibilidade e/ou aos sem poder tende a ser equivocadamente negada a credibilidade - devemos reconhecer que há um fenômeno de injustiça epistêmical3 (FRICKER, 1998, p. 170. Itálicos meus).

Para Fricker, fora do estado de natureza, há forças políticas e novas formas de competição e interesse próprio que fazem com que indivíduos e instituições adquiram vantagens práticas ao parecerem dotados de autoridade racional quando na verdade não são; e ao fazerem como que outras pessoas não pareçam dotadas dessa autoridade quando na verdade elas são (FRICKER, 1998, p. 172). Ou, como Lorraine Code defendeu, "os espaços retóricos que a sociedade legitima geram presunções de credibilidade e confiança que se associam diferentemente de acordo com como falantes e intérpretes estão posicionados dentro dela" (CODE, 1995, p. 60). Considere, por exemplo, a situação de uma pessoa negra no sul racialmente segregado dos EUA, na década de 1930. A participação de uma pessoa negra como compartilhadora de informações numa sociedade como essa está limitada por uma ausência de poder social por parte dela, que faça com que ela seja presumida como merecedora de crédito epistêmico em diversas áreas de interesse informacional social. Isso não quer dizer, necessariamente, que ela não possui autoridade racional sobre uma gama de assuntos deliberados nessa sociedade. $\mathrm{O}$ ponto é que, ainda que ela possua e uma pessoa branca não possua essa autoridade, existiria uma tendência em se atribuir credibilidade à pessoa branca em detrimento da pessoa negra. O mesmo poderia ser dito sobre a participação epistêmica de mulheres em contextos tomados por sentimentos misóginos e machistas. Ou ainda de estrangeiros em contextos de xenofobia saliente.

O ponto geral aqui é que, sempre que houver esse descompasso entre a posse de autoridade racional e as propriedades indicadoras funcionais em operação na sociedade, por conta de, por exemplo, um preconceito de identidade, haverá o que Fricker chamou de injustiça epistêmica: ${ }^{14}$ uma falha na concessão de credibilidade epistêmica quando ela é devida - ou na não concessão dela quando ela é indevida. ${ }^{15}$ Quando esse é o caso, Fricker afirma, o mecanismo de

\footnotetext{
${ }^{13}$ Fricker menciona como exemplo o cenário relatado por Steven Shapin (1994, p. 75), segundo o qual haveria na Inglaterra vitoriana uma cultura de veracidade "cavalheirista" na qual ser um cavalheiro (um gentleman, termo de cunho social e moral para identificar membros da aristocracia e novos ricos da época) seria propriedade indicadora funcional central para autoridade racional mas não apenas sobre questões particulares. Seria uma chave para identificar bons informantes de modo global. Em contrapartida, ser uma mulher, ou ainda um homem que não fosse um cavalheiro, seria uma chave para identificar maus informantes. Nesse cenário, segundo Shapin, os sistemas institucionais de exclusão eram tão eficazes que o reconhecimento da desigualdade de gênero na participação das trocas informacionais não era sequer recorrente, como eram os comentários sobre a falta de nobreza e sobre a disposição para a servidão desses grupos excluídos.

${ }^{14}$ Em seu livro seminal Epistemic injustice (2007), Fricker oferece um tratamento compreensivo do fenômeno da injustiça epistêmica. É lá que se encontra a fonte mais detalhada até então dessa discussão.

15 Esse tipo particular de injustiça epistêmica é o que Fricker (2007, p. 1) chama de injustiça testemunhal.
} 
identificação de bons informantes estabelecido por Craig se degenera no contexto social atual e vira um mecanismo de discriminação epistêmica (FRICKER, 1998, p. 172). Um sujeito que é vitimado por uma discriminação fica parcial ou completamente impedido de participar ativamente do compartilhamento de conhecimento nessa comunidade - mesmo que ele esteja em posição de protagonizar esse compartilhamento.

Note que Fricker não quer dizer que, do ponto de vista da abordagem de Craig, mulheres, negros, estrangeiros, etc. não têm conhecimento, por não serem reconhecidos como bons informantes. A correlação entre os dois conceitos é apenas evolutiva e não marca uma equivalência necessária entre conhecedores e bons informantes. Esses sujeitos epistêmicos são, de fato, conhecedores. Mas o são à revelia da norma de credibilidade que, em tempos hipotéticos remotos do estado de natureza, determinava quem era e quem não era bom informante. Nosso conceito de conhecimento capta algumas extensões intuitivas e o fato de sua genealogia ser rígida não vai implicar em uma mudança nos casos que identificamos com tal atualmente. Fricker aponta que é justamente esse desprendimento da sua história evolutiva que mostra que precisamos olhar mais atentamente para os aspectos políticos das nossas práticas epistêmicas.

Com esse ponto em mente, Fricker faz uma defesa de pelo menos duas posições mais centrais. Primeiro, ela defende que uma avaliação completamente "veritista" da epistemologia tradicional precisa receber essa luz politizada (FRICKER, 1998, p. 173). Uma avaliação epistêmica que ignora todos os aspectos políticos e as relações de poder envolvidas na prática epistemológica cotidiana ignora também as maneiras através das quais a correlação adequada entre a autoridade racional e a credibilidade não é alcançada e, por consequência, a identificação confiável de boas fontes de informação. Se buscamos mais verdades, precisamos entender os mecanismos que nos impedem de chegar a elas com mais frequência. E é essa a limitação da explicação genealógica de Craig. Ele fala do que valorizamos quando falamos em conhecimento, quais disposições e relações temos em mente quando usamos o conceito. Mas falha em captar, na sua história de objetivação, como as normas de credibilidade, na passagem do estado de natureza para o contexto social complexo, passam a captar propriedades indicadoras funcionais e não, necessariamente, propriedades indicadoras de fato.

O segundo ponto de Fricker é que um reducionismo total da prática epistêmica a questões de poder social também não se sustenta. Em particular, a explicação que Craig oferece, a partir de uma preocupação normativa acerca do nosso uso do conceito de conhecimento, é uma explicação preocupada em formular uma concepção de autoridade racional que independe de poder social. Do mesmo modo, a explicação valorativa que Fricker irá desenvolver em seguida (2009), através da noção de resiliência epistêmica também tem existência independente de questões sobre poder social. Uma coisa é defender que essas noções e a normatividade a elas atrelada podem ser frustradas por questões políticas. Outra completamente diferente é defender que todas essas noções expressam apenas poder social e nada mais. 
Para Fricker, o trabalho de Craig é uma defesa indireta do papel da norma de credibilidade, que passou a ser bastante comum nos debates em epistemologia social. Mas essa norma de credibilidade precisa ser entendida também do ponto de vista de uma genealogia social, do mesmo modo que o conceito de conhecimento. O conhecimento está intimamente conectado aos aspectos políticos e sociais da nossa vida em comunidade, às estruturas de poder social que orientam nossas práticas epistêmicas, justamente porque é necessariamente dependente dos resultados entregues por essa norma de credibilidade. Ainda que identifiquemos aquilo que dá valor ao conhecimento através da ideia de que essa noção nos aponta bons informantes ou informações estáveis, resilientes, é importante que entendamos que esses resultados podem ser corrompidos pelas estruturas de poder social presentes em uma comunidade.

Considero que esse ponto pode ser reforçado se pensarmos na persistência das falhas epistêmicas causadas por essas estruturas de poder, a partir do que Kristie Dotson (2014, p. 121) chamou de resiliência de sistemas epistêmicos. É importante não confundir esse sentido de resiliência adotado por Dotson e o sentido utilizado por Fricker. Mas é importante também reconhecer o que os aproxima. Para Dotson, nosso ambiente epistêmico é o espaço no qual realizamos nossas trocas e interações epistêmicas; e esse espaço é marcado por três características salientes: a contextualização dos conhecedores, a interdependência dos nossos recursos epistêmicos; e a resiliência dos nossos sistemas epistêmicos (DOTSON, 2014, p. 120). As duas primeiras características parecem estar captadas pelo que discutimos até então. A interdependência podendo ser vista na ideia de busca por bons informantes e por informações estáveis. E a contextualização podendo ser avaliada em termos do posicionamento social dos agentes, como defendido por Fricker. A resiliência de sistemas, por sua vez, é um elemento novo na nossa discussão, mas que acredito pode ser avaliado em termos do que discutimos até aqui.

Por sistemas epistêmicos, Dotson entende nossos modos de vida epistêmicos - nossos "imaginários sociais operativos e instituídos, nossos hábitos de cognição, nossas atitudes direcionadas a conhecedores, e/ou qualquer sensibilidade relevante que encoraja ou dificulta a produção de conhecimento" (DOTSON, 2014, p. 121). Quando ela diz que a resiliência desse sistema é uma das características do nosso ambiente epistêmico, ela quer dizer que esse sistema é altamente estável. "Para o bem ou para o mal" (DOTSON, 2014, p. 122). Por um lado, é importante que ele seja estável, afinal, como vimos em Fricker, a estabilidade é um sinal de qualidade epistêmica. Queremos que nosso sistema seja estável, por exemplo, em nos entregar resultados adequados para nossas avaliações feitas com base na norma adequada de credibilidade. A lição retirada da noção de resiliência epistêmica utilizada por Fricker, e pela ideia de bom informante de Craig, é que precisamos de uma maneira de identificar boas fontes de conhecimento e boas informações de um modo em que ambos sejam resistentes ao teste do tempo. Um sistema epistêmico resiliente seria um que entregaria resultados resistentes nesse sentido. 
Mas essa resistência vem também com algum custo. A resiliência dos nossos sistemas, segundo Dotson, significa também que a magnitude de perturbação que ele deve sofrer para que corrija suas falhas é muito grande (DOTSON, 2014, p. 121). Quando Craig defende que o conceito de bom informante passou por um processo de objetivação até chegar a ser o nosso conceito de conhecedor, ele está dizendo que o conceito ancestral passou pelos mecanismos desse sistema epistêmico até sair mais forte e mais resistente ao escrutínio do investigador exigente. As normas de credibilidade que se sedimentaram nesse processo são parte tanto dos nossos hábitos de cognição quanto das nossas atitudes direcionadas a outros conhecedores, dois elementos presentes naquilo que Dotson entende por sistema epistêmico. Desse modo, entender as falhas que tanto Fricker quanto Dotson identificam no nosso trabalho epistêmico cotidiano, através daquilo que a primeira chama de injustiças epistêmicas, e do que a segunda chama de opressôes epistêmicas (DOTSON, 2014, p. 115), pode passar justamente pelo reconhecimento de uma história genealógica como a que Craig nos oferece. E também pela ideia de que, ainda que esteja arraigada de forma apolítica no nosso sistema enquanto paradigma de avaliação de outros sujeitos epistêmicos, precisamos fazer como Fricker e insistir na politização do nosso entendimento dessa norma, mesmo que isso signifique causar perturbações constantes ao nosso sistema epistêmico.

\section{CONCLUSÃO}

Nesse artigo eu quis apresentar duas maneiras de conceber uma explicação genealógica do conceito de conhecimento. A primeira delas através da hipótese do estado de natureza elaborada por Craig, na qual conhecimento é compreendido como um conceito evoluído a partir do conceito de bom informante. Minha ideia foi mostrar como Craig construiu sua abordagem acerca desse conceito e em que sentido podemos traçar um paralelo entre essa abordagem e a explicação valorativa de Fricker sobre o mesmo conceito. Em seguida, eu apresentei e discuti o desenvolvimento social que Fricker oferece à genealogia de Craig, onde ela defende que as noções de bom informante e de conhecimento são necessariamente dependentes do estabelecimento de uma norma de credibilidade. Sua posição é que o reconhecimento do papel dessa norma pode nos ajudar a dar o salto a partir da genealogia de Craig para uma genealogia social do conceito de conhecimento, entendendo como aspectos políticos passam a influenciar nossa prática epistêmica uma vez que saímos do estado de natureza e chegamos em um cenário social complexo. Por fim, defendi uma ilustração a partir do trabalho de Kristie Dotson de como essas abordagens genealógicas não só podem explicar a tendência à confiabilidade e à estabilidade dos nossos sistemas epistêmicos como podem também explicar uma maneira de modifica-los quando eles ajudam a perpetuar falhas na nossa conduta epistêmica em comunidade. 


\section{REFERÊNCIAS BIBLIOGRÁFICAS}

CODE, Lorraine. Rhetorical spaces: Essays on gendered locations. New York. Psychology Press, 1995.

CRAIG, Edward. Knowledge and the state of nature: An essay in conceptual synthesis. Oxford: Clarendon, 1990.

The practical explication of knowledge. Proceedings of the Aristotelian Society, v. 87, n.1, p. 211-226, 1986.

DOTSON, Kristie. Conceptualizing epistemic oppression. Social Epistemology, v. 28, n. 2, p. 115-138, 2014.

FRICKER, Miranda. Rational authority and social power: Towards a truly social epistemology. Proceedings of the Aristotelian Society, v. 98, n.1, p. 159-177, 1998.

Epistemic injustice: Power and the ethics of knowing. Oxford University Press, 2007.

The value of knowledge and the test of time. Royal Institute of Philosophy Supplement, v. 64, n.1, p. 121, 2009.

GRECO, John. Knowledge as credit for true belief. In: DEPAUL, Michael; ZAGZEBSKI, Linda (eds.). Intellectual virtue: perspectives from Ethics and Epistemology. Oxford: Oxford University Press, 2003. p. 111-134.

KUSCH, Martin. Testimony and the value of knowledge. In: HADDOCK, Adrian; MILLAR, Allan; PRITCHARD, Duncan (eds.). Epistemic value. Oxford: Oxford University Press, 2009. p. 60-94.

PLATO. Protagoras and Meno. Trad. de Adam Beresford e Leslie Brown. London: Penguin Classics, 2005.

PRITCHARD, Duncan. The structure of sceptical arguments. The Philosophical Quarterly, v. 55, n. 218, p. 37-52, 2005.

SHAPIN, Steven. A social history of truth: Civility and science in seventeenthcentury England. Chicago: University of Chicago Press, 1994.

ZAGZEBSKI, Linda. Virtues of the mind: An inquiry into the nature of virtue and the ethical foundations of knowledge. New York: Cambridge University Press, 1996. 